\title{
Quem é afinal Julieta de Luna, diretora do Almanaque das Senhoras?
}

\author{
ISABEL LOUSADA \\ Universidade Nova de Lisboa - Lisboa - Portugal
}

Como ficou registado no Catálogo Senhoras do Almanaque, que Vania Pinheiro Chaves, Carlos Francisco Abreu e Silva e eu própria editamos pela Biblioteca Nacional de Portugal, um dos frutos mais importantes da investigação que fizemos para construir aquele inventário foi, provavelmente, a descoberta de que Julieta de Luna, até hoje tida como mulher e valorizada por ter sido uma das diretoras do Almanaque das Senhoras, ao substituir Maria O'Neill, em 1925, era, na verdade, um homem.

O próprio Almanaque de Lembranças contribuiu, durante alguns anos, para que esse engano se mantivesse, uma vez que consentiu que a pretensa condição feminina de Julieta de Luna fosse posta em evidência, em inúmeros poemas que lhe foram dedicados em diversos anuários, entre os quais os destinados aos anos de 1920, 1922, 1923. Só no Novo Almanaque de Lembranças Luso-Brasileiro para o ano de 1929 - onde ainda se encontram poemas oferecidos à "D." Julieta de Luna - é que Armando de Lima Pereira resolve pôr a nu a verdadeira identidade da diretora do Almanaque das Senhoras. No longo artigo de abertura do referido volume, Lima Pereira lamenta a morte de José Leoni Palermo de Faria, conhecido charadista e colaborador do Almanaque de Lembranças, referindo, por outro lado, que o ilustre falecido comparecia também na coletânea com os pseudónimos Julieta de Luna e Alfacinha.

Pela importância de que se reveste este documento em função sobretudo da novidade que aporta consideramos oportuno transcrevê-lo e publicá-lo na Navegações, cuja reconhecida qualidade e larga difusão no meio acadêmico possibilitará a correcção de um dado da maior relevância para o conhecimento da imprensa em Portugal, e mais especificamente, da chamada imprensa feminina.

A figura e a obra de José Leoni Palermo de Faria ou J. L. P. F - iniciais com que assina tantas vezes - foram devidamente apresentadas por Armando de Lima Pereira (que também usava o acrónimo ARIEREPAMIL), no Novo Almanaque de Lembranças Luso-Brasileiro para o ano de 1929, volume publicado imediatamente a seguir à morte do homenageado. $\mathrm{O}$ artigo in memoriam é aqui trazido novamente à luz, a catorze anos da celebração do centenário do falecimento de Palermo de Faria, sem que tenhamos a veleidade de acrescentar muito ao belo e documentado texto que se transcreve.

$\mathrm{Na}$ passagem do centenário das comemorações da Grande Guerra, iniciada em 1914, não podemos, contudo, deixar de lembrar o insigne militar que foi também Palermo de Faria - Capitão de Infantaria do Corpo Expedicionário Português, gaseado como tantos outros e cujas insígnias, patentes na foto que incluímos, espelham o reconhecimento e notoriedade que lhe concederam em vida que, apesar de breve, foi assinalável aos mais diversos títulos. Esta nota a que juntamos a transcrição oferecida em seguida aos leitores das páginas do Almanaque cala bem fundo, tal como ontem, hoje. Vidas singulares que ultrapassam o portal dos tempos e se tornam presente. A seu tempo a ele, que também é (foi) ela, voltaremos.

Note-se, ainda, que José Leoni Palermo de Faria e Armando de Lima Pereira são casos particularmente ricos em leituras, cujo fio é o da multiplicidade de pseudónimos, que seria de interesse prosseguir. Mas, por ora, fixaremos o nosso olhar no pseudónimo Julieta de Luna. Parece plausível acreditar que tal pseudónimo, entre a homenagem e o disfarce, terá sido escolhido pelo "Alfacinha" utilizando o segundo nome de sua mulher Laura Julieta de Almeida Palermo de Faria - acrescentado de um possível acrónimo do seu prenome (Laura > Lua) passado para o italiano "Luna", a evocar as raízes de dois nomes do charadista.

Escolhido o lado lunar e funcionando de tal modo bem, até hoje Julieta de Luna permaneceu na qualidade incontestada, "indesmentida", como diretora do Almanaque das Senhoras, nos mais diversos repositórios enciclopédicos e científicos. A nossa descoberta permitenos apontar justificação mais segura para o encerramento da publicação daquele Almanaque ${ }^{1}$, cujo último número coincide com o do ano da morte do, até então, diretor da "Seção Charadística" do Almanaque de Lembranças.

No próprio Almanaque de Lembranças para 1929 indica-se a suspensão definitiva do Almanaque das Senhoras (NALLB, 1929, p. 27). 
A um só tempo, são duas as perdas. Em ambos anuários mas em muitas mais assinaturas. Rude golpe na multiplicidade de protagonistas a que deu corpo, nas distintas vozes do uno, desvendado o mistério de ser singular afinal, num só corpo, descobrindo a mulher a que deu vida pelo exercício da escrita, assinando como Julieta de Luna; assim dirigiu uma publicação de relevo nas letras portuguesas coevas mais dirigida ao sexo feminino, continuando a liderança de Maria O’Neill, desde 1926; aí exibe o termo "Luna" evocando o símbolo feminino que é simultaneamente o do renascimento, da transformação matriarcal, tal como enquanto continuador de "In-Justo", no Novo Almanaque de Lembranças Luso-Brasileiro, o vinha já fazendo antes, desde 1916, revelando quiçá, o lado mais solar da sua compleição, desta feita, patriarcal.

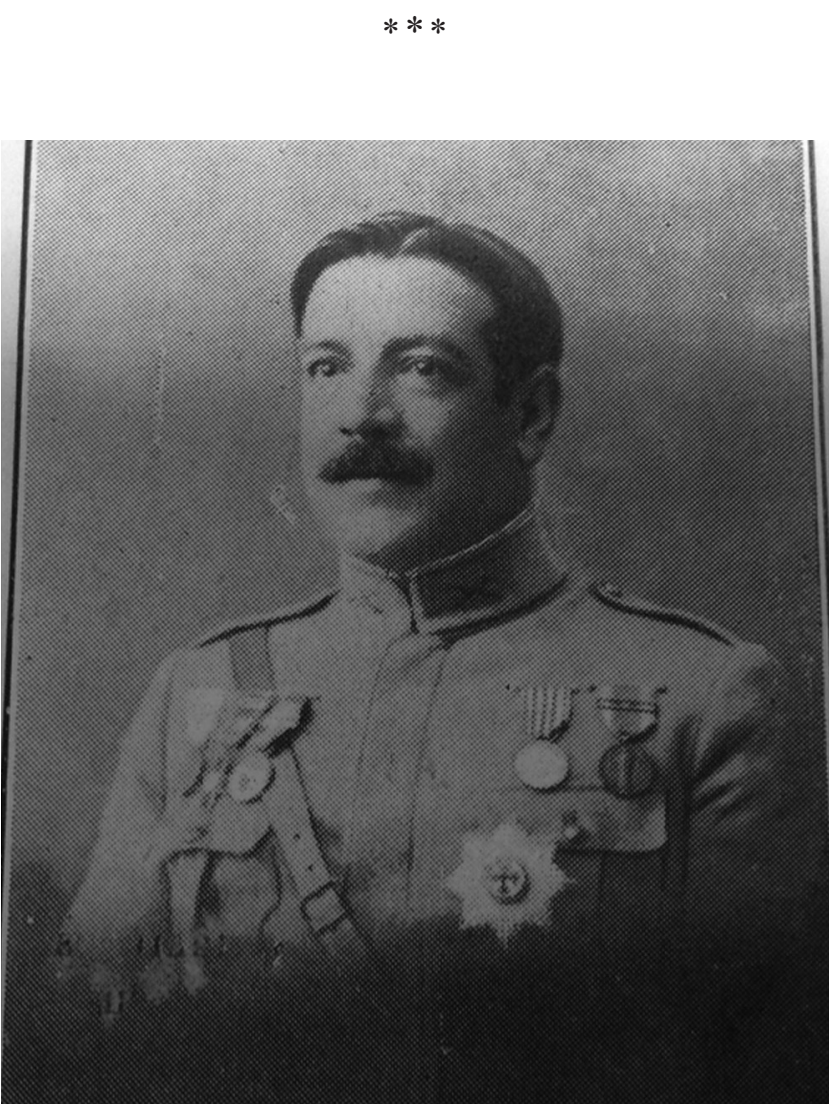

JOSÉ LEONI PALERMO DE FARIA

J. L. P. F.

Faleceu no dia 9 de Julho, quase inesperadamente, o nosso querido Director José Leoni Palermo de Faria, (J. L. P. F.).

Com este tristissimo acontecimento, está de luto o "Almanaque de Lembranças" e, conseqùentemente, o charadismo luso-brasileiro.

A noticia da sua morte causou-nos a mais dolorosa das impressões!
Havia ainda poucos dias que tinhamos estado em sua casa, onde iamos freqùentes vezes, encontrando-o numa magnifica disposição de espirito, conversando e rindo animadamente.

Conquanto soubessemos por informações particulares obsequiosamente prestadas por um médico amigo de que o seu mal éra de gravidade, nunca supozemos que tão cedo se daria o triste desenlace.

Nada fazia prever que a sua robusta compleição física sucumbiria tão rapidamente aos estragos da doença, pois ainda na vespera do dia em que faleceu ele esteve dando a ultima demão neste "Almanaque», ao qual dedicava um grande e enternecido amor.

Desde 1916 que Palermo de Faria, após o afastamento do brilhante "In-justo", dirigia com a maior proficiencia este anuario, e do valor da sua obra charadistica falam bem alto os treze volumes onde ele deixou dispersos os folgôres do seu belo talento de produtor, colaborando com varios pseudonimos, entre os quais se destacam os de "J. L. P. F.", "Julieta de Luna" e "Alfacinha".

O ilustre extinto que era, - mercê do seu grande valor moral e intelectual e da enorme expansão do "Luso", - o charadista português mais conhecido em Portugal e Brasil, gosava, entre os numerosos cultores da interessante Arte Charadistica, das maiores amisades e simpatias. Dotado de uma natural bondade e cativante afabilidade de trato, recebia sempre com o maior agrado todos os confrades que se lhe dirigiam pessoalmente ou que por escrito lhe pediam esclarecimentos sobre qualquer trabalho do "Almanaque".

Era Presidente da Direcção da "Tertulia Edipica", a mais conceituada agremiação charadistica portuguêsa, que sofreu com a sua morte uma perda irreparavel, pois J. L. P. F. era um dos seus mais activos propagandistas e um dos seus melhores dirigentes.

O malogrado Director do "Luso" era considerado como um Mestre da Arte de OEdipo. Os seus conselhos eram sempre respeitosamente ouvidos e acatados pela sua incontestavel autoridade no assunto.

Com o pseudonimo de "Julieta de Luna" dirigiu tambem desde 1925 o conhecido "Almanaque das Senhoras" que este ano suspendeu, definitivamente, a publicação.

J. L. P. F. foi um trabalhador incansavel; todos os momentos que tinha livres dedicava-os ao seu entretenimento predilecto, - o charadismo. Alem da directoria dos dois "Almanaques" já citados e da T. E., estava trabalhando com todo o entusiasmo na factura de um "Manual da Pansofla ou o A.B.C. do Charadismo", que a traiçoeira morte, infelizmente, não deixou concluir.

A "Tertulia Edipica" em homenagem ao seu desditoso Presidente deve completar essa obra e lançala no mercado onde, certamente, terá o acolhimento a 
que o nome prestigioso do seu iniciador tem incontestavel direito.

Damos, a seguir, algumas notas biograficas do nosso querido morto:

José Leoni Palermo de Faria nasceu a 13 de Maio de 1883, era natural de Lisboa, filho de José Francisco Palermo de Faria, já falecido e de D. Mathilde Leoni da Fonseca Faria, felizmente ainda viva, contando a bonita idade de 73 anos.

Era casado com D. Laura Julieta de Almeida Palermo de Faria, tendo deixado tres filhos, dois dos quais ainda menores, D. Maria Isabel, Fernando Hugo e José Alexandre Palermo de Faria.

O insigne charadista foi um distintissimo oficial do exercito, tendo-se alistado como voluntario no regimento de artilharia 1, sendo incorporado no dia 1 de Agosto de 1900.

Foi promovido a alferes em 1903, a tenente em 1907, a capitão em 1914 e a major em 1918.

Foi louvado na E. P. de Infantaria por ter sido considerado distinto na instrucção de esgrima no periodo de 1902-3.

Possuia a medalha de prata de comportamento exemplar, a comenda de Aviz, a medalha comemorativa das campanhas do exercito português com a legenda: "França 1917-18 e a medalha da Vitoria.

Tinha, tambem, as medalhas de expontanea e valiosa cooperação e de agradecimento da Cruz Vermelha.

Foi louvado porque sendo ajudante da $1 .^{a}$ brigada do C. E. P. desempenhou com especial competencia, inteligencia e dedicação as funções a seu cargo, revelandose um excelente auxiliar do comando e contribuindo muito pelo seu esforço em todas as circunstancias para fazer elevar o bom nome da brigada.

Exerceu durante alguns anos o cargo de Directorgerente da Cooperativa Militar, sendo ali muito estimado por todo o pessoal.

O saudoso major Palermo de Faria, como é já sabido, tomou parte na Grande Guerra, e foi uma das suas inumeras vitimas, pois morreu em virtude dos gazes asfixiantes.

De um relatorio que ele escreveu transcrevemos a seguinte curiosa passagem que se refere ao seu gazeamento:

"Durante a minha estada em França, servi primeiramente como ajudante do $2 .^{\circ}$ regimento de infantaria e desde 1 de Abril, por motivo da organisação das brigadas, como ajudante da $1 .{ }^{a}$ brigada de infantaria. Foi nesta ultima qualidade que, na noite de 12-13 de Julho de 1917, tendo o inimigo efectuado um 'raid' sobre o sector 'Ferme du Bois', então ocupado pelo batalhão de infantaria 22 , fui como delegado da Brigada verificar como, no cumprimento da ordem d'ali emanada, se efectuava o reforço da 2. ${ }^{\text {a }}$ linha e reocupação da $1 .^{\text {a }}$, realisado pelo batalhão de infantaria 21 , que se encontrava na posição de ‘apoio' e fôra mandado avançar no desempenho daquela missão.

"Quando cheguei ao local da séde do batalhão, estava o inimigo fazendo um forte bombardeamento com granadas, algumas das quais eram de gaz; pouco depois uma destas rebentou mais proximo, vê-se uma fumarada densa, sente-se um cheiro acre e eu tentei pôr a mascara; não tive tempo para isso, senti uma sufocação, uma vertigem, e fui arrastado para o posto de socorros, juntamente com dois ou tres soldados em iguais condições."

A seguir descreve os horrores das nauseas provocadas por esse terrivel veneno que causou tantas mortes e que, decorridos alguns anos, tambem o não poupou...

Ao escrever, no anterior volume deste anuario, a biografia do humorista inimitavel que se chamou André Brun, J. L. P. F. disse que ele morria apenas com 45 anos, no posto de major e por efeito dos gazes asfixiantes com que foi atacado na campanha da Flandres.

Por fatal coincidencia, Palermo de Faria morreu tambem, com a mesma idade, com igual posto de major e em consequencia dos gazes com que o inimigo, traiçoeiramente, o atacou...

São já decorridos dez anos e ainda se estão fazendo sentir os sinistros efeitos desse horrivel flagelo! Palermo de Faria, como tantissimos outros portugueses, foi morto á traição, com uma arma para a qual eu não encontro qualificativo ... ele, que era um caracter feito de lealdade e nobresa, ele, que foi sempre um bom, em cuja alma só se albergavam os mais puros sentimentos!

Infeliz amigo!

Havemos de recordar sempre com a mais profunda saudade a leal e sincera estima que nos dedicou e á qual temos a absoluta certeza de que não ficámos a dever nada, pois pagámos-lhe com as nossas qualidades mais afectivas. Agora, resta-nos apenas honrar a sua saudosa memoria!

Que a sua alma diamantina tenha o descanso eterno!

Julho de 1928.

Armando de Lima Pereira

(ARIEREPAMIL)

Recebido: 23 de outubro 2014 Aprovado: 13 de novembro 2014 Contato: iclousada@gmail.com 